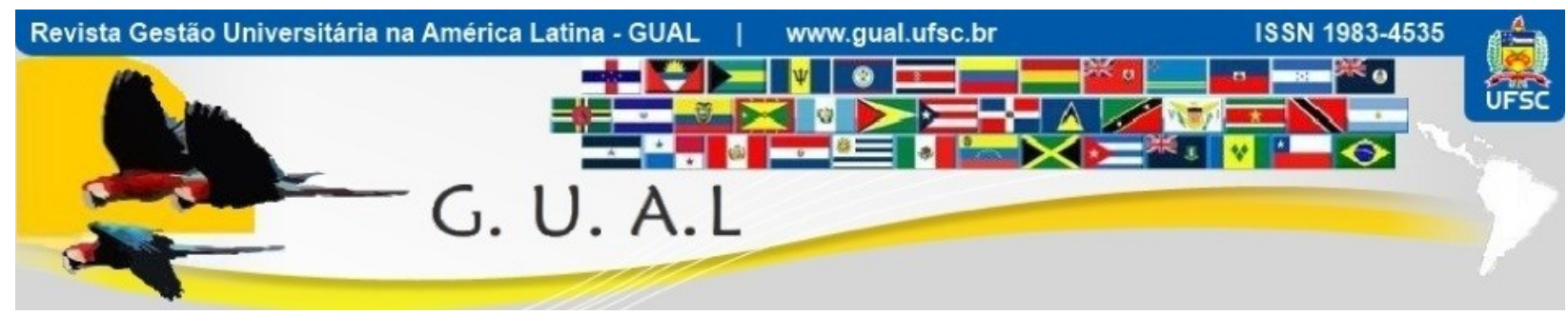

DOI: http://dx.doi.org/10.5007/1983-4535.2013v6n3p232

\title{
OS FATORES DE MOTIVAÇÃO NA DEFINIÇÃO DE ESTUDANTES ESTRANGEIROS EM MOBILIDADE ACADÉMICA INTERNACIONAL NO BRASIL
}

\section{MOTIVATION FACTORS OF THE DEFINITION OF FOREIGN STUDENTS IN INTERNATIONAL ACADEMIC MOBILITY IN BRAZIL}

Claudia Cristiane dos Santos Silva, Mestranda Escola Superior de Propaganda e Marketing - ESPM claudia@espm.br

Manolita Correia Lima, Doutora Escola Superior de Propaganda e Marketing - ESPM mclima@espm.br

Viviane Riegel, Mestre

University of Maryland viviane_riegel@terra.com.br

Recebido em 30/abril/2013

Aprovado em 12/julho/2013

Sistema de Avaliação: Double Blind Review

Esta obra está sob uma Licença Creative Commons Atribuição-Uso. 


\title{
RESUMO
}

$\mathrm{Na}$ intenção de ampliar os estudos a respeito da mobilidade acadêmica e suas diversas expressões, esse artigo tem por objetivo compreender os diferentes fatores de motivação no processo de definição por estudantes estrangeiros, para um período de estudos em outro país. Compreender os fatores que podem influenciar essa escolha, no contexto da mobilidade espontânea, no que concerne ao país de destino, passa por analisar aspectos pessoais e acadêmicos, assim como a possível relevância da imagem de destino, resgatando os elementos que compõem a imagem desse lugar. Considerando essa demanda, foi realizado um estudo de caráter exploratório, cujo material empírico coletado por meio de entrevistas semiestruturadas foi analisado a partir da orientação das categorias de motivação. Os resultados revelaram que não há um componente padrão que oriente a escolha do destino, mas uma interação entre os diferentes aspectos, incluindo os elementos que compõem a imagem do país.

Palavras-chave: Internacionalização do Ensino Superior. Mobilidade Acadêmica Internacional. Motivações. Imagem do Destino.

\begin{abstract}
Intending to expand the studies about the academic mobility and its various expressions, this article aims to understand the different motivating factors in the definition process for foreign students for a period of study in another country. Understanding the factors that can influence this choice in the context of spontaneous mobility, regarding the country of destination, going through the analysis of personal and academic aspects, as well as the possible relevance of the destination image, rescuing the elements that make up the image of this place. Considering this demand, the study was conducted on an exploratory basis, and its empirical data collected through semi-structured interviews were analyzed from the orientation of the categories of motivation. The results revealed that there is not a standard component that sets the choice of destination, but an interaction between the different aspects, including the elements that make up the country's image.
\end{abstract}

Keywords: Internationalization of Higher Education. International Academic Mobility. Motivation. Destination Image. 


\section{CONTEXTUALIZAÇÃO E DEFINIÇÃO DOS OBJETIVOS}

No contexto da modernidade, a abordagem sobre o tema internacionalização da educação superior parece não fazer sentido se desacoplado do fenômeno da globalização. Pois, os imperativos de um mundo globalizado emergem também no âmbito da educação, onde sob o discurso da necessidade de recrutar trabalhadores que tenham desenvolvido competências que os permitam transitar em outras culturas, falar outros idiomas, pensar de forma global, encerra por fomentar as estratégias de internacionalização no setor.

Esse cenário vem sendo alterado de forma proeminente em conseqüência da globalização das sociedades e das economias, podendo se manifestar por meio do aumento exponencial da concorrência por estudantes internacionais, do crescimento da cooperação transfronteiriça, do desenvolvimento de programas e do surgimento de um comércio no âmbito das instituições de educação superior internacionais. Outro sinal dessa alteração está na mudança de posição de países como Índia e China na economia mundial. Na arena de ensino superior, esses países desempenham um papel significativo quando se observa a quantidade de estudantes que buscam por uma experiência acadêmica internacional (DE WIT, 2010). Para se dimensionar esse movimento, segundo os dados da OCDE (Organização para Cooperação e Desenvolvimento Econômico), em 2009, 52\% dos estudantes estrangeiros matriculados ao redor do mundo eram provenientes do continente asiático, principalmente da China, Índia e da República da Coréia.

Diante desse contexto, torna-se factível explorar o elemento mais visível na internacionalização do ensino superior, a mobilidade acadêmica. No âmbito do Brasil, cabe resgatar esse componente no período que antecede a fundação da primeira universidade. Por três séculos, os estudantes que desejassem ingressar no ensino superior deveriam seguir para as terras além-mar, a fim de diplomarem-se nas universidades de Portugal, cujas opções da época eram a Universidade de Coimbra ou a menos prestigiosa Universidade de Évora (COWEN, 2002).

A primeira universidade criada no Brasil, data da década de 1930. No entanto, não se trata de uma universidade nacional. A USP (Universidade de São Paulo), instituição criada pela elite política do Estado de São Paulo, região econômica mais rica do Brasil, desde o início esteve voltada para o mundo. Essa intenção está caracterizada no próprio corpo docente, formado por professores europeus, e frequentada por filhos dos imigrantes europeus (SCHWARTZMAN, 2006). Considerando os pilares que sustentaram sua fundação, seu 
tamanho, produção de pesquisa e os recursos mobilizados, a USP poderia almejar o título de universidade internacional. Contudo, ao se ponderar a forma como seus estudantes são selecionados e o número de estudiosos estrangeiros, bem como o uso quase exclusivo do português, ela caracteriza-se como uma instituição local (SCHWARTZMAN, 2006). Isso não significa que a Instituição esteja indiferente à importância acadêmica decorrente da internacionalização e por isso mesmo trabalha com uma política de cooperação internacional. Eventos como o primeiro encontro ${ }^{1}$ de Gestão de Relações Internacionais, realizado em agosto de 2011, "USP pensa a internacionalização", em que o objetivo era discutir a integração das atividades de internacionalização da universidade, reflete a intenção da instituição em trilhar esse caminho.

Assim como a USP, outras instituições de educação superior, brasileiras, também estão imbuídas desse propósito, onde a ação mais recente é o estabelecimento de acordos bilaterais com universidades estrangeiras. Conforme informações do relatório Education at a Glance 2011, chancelado pela OCDE, em 2008 o Brasil enviou 32.133 estudantes para realizar um período de estudos no exterior. No entanto, ainda que os dados sobre o acolhimento não sejam tão expressivos, se comparados aos estoques de estudantes enviados, o fato é que no mesmo ano o país acolheu 3.542 estudantes estrangeiros para a realização de intercâmbios acadêmicos (OCDE, 2011).

Para contextualizar o fenômeno mundialmente, é necessário verificar o processo de mobilidade acadêmica nos outros países. Em 2009, de cada 100 estudantes, quase três estudavam fora do país de origem, ou seja, mais de 3,7 milhões de estudantes freqüentavam cursos superiores no exterior e isso representou um aumento de $6,4 \%$, em relação a 2008 . Os estudantes internacionais representavam mais de $20 \%$ dos efetivos dos programas de pesquisa de alto nível nos Estados Unidos, Reino Unido, Canadá, Nova Zelândia, Bélgica e Suíça (OCDE, 2011). Os números relativos à mobilidade internacional dos estudantes apenas reflete assimetrias: em 2008 foram enviados 177.995 (0,9\% do total de inscritos no ensino superior) e acolhidos 57.709. As regiões que mais hospedaram estudantes latino-americanos foram América do Norte e Europa Ocidental (73,7\%). Contudo, no mesmo período, os países da América do Norte e da Europa Ocidental enviaram 486.981 estudantes (1,4\% do total de

\footnotetext{
${ }^{1}$ http://www.ccint.usp.br/gerint/ - consultado em novembro de 2011
} 
inscritos no ensino superior) e acolheram 1.841.933 (UNESCO, 2010). A assimetria observada tende a ser reforçada quando se considera que o grosso da expansão do ensino superior nos países periféricos e semi-periféricos ocorrerá nas próximas décadas (ALTBACH, 2009).

Assim sendo, torna-se oportuno investigar o que atrai esses estudantes ao Brasil. A própria literatura aponta para mais de vinte aspectos que podem influenciar os estudantes internacionais na escolha do país de destino. Esses estão relacionados às categorias sociocultural, acadêmico-cultural, econômico-comercial e administrativo (LIMA; CONTEL, 2011). No estudo realizado por Silva e Lima (2011), observou-se que a imagem do destino pode ser determinante para a escolha do lugar onde o estudante viverá sua experiência acadêmica (SILVA; LIMA, 2011). Portanto, no âmbito desse artigo, investigar-se-á quais são os aspectos pessoais e acadêmicos, assim como aqueles relacionados à imagem do país que podem ser relevantes para os estudantes estrangeiros decidirem pelo Brasil para a realização de um período de estudos. No exercício da compreensão dessas questões, esse texto está estruturado em mais quatro sessões. A segunda trata dos recursos metodológicos utilizados para a coleta e análise dos dados. A terceira contém o referencial teórico, que apresenta um painel sobre a mobilidade acadêmica e versa sobre a discussão acerca da imagem do destino. A quarta sessão desenvolve a discussão dos materiais empíricos coletados.

\section{ASPECTOS METODOLÓGICOS}

Dada a insuficiência de informações acerca de aspectos que influenciam as escolhas de estudantes estrangeiros pelo Brasil, este artigo constitui-se a partir de uma investigação de natureza exploratória, orientada por uma abordagem de caráter qualitativo. Para tanto, foram realizadas entrevistas em profundidade. Apesar de guiadas por um roteiro semi estruturado, ele serviu apenas de âncora para as perguntas que seriam pormenorizadas em consonância com as respostas desenvolvidas por cada um dos intercambistas entrevistados. A razão de ser do referido roteiro consistiu em apoiar o entrevistador no sentido de recordar as questões chave no decorrer da entrevista (GODOI; MATTOS, 2006). A escolha dessa técnica de coleta de materiais ('entre - vistas') está em consonância com a abordagem metodológica escolhida uma vez que privilegia a expressão verbal com o objetivo de compreender a realidade na perspectiva dos atores sociais diretamente envolvidos. Dessa forma, a pesquisa pode se 
beneficiar do acesso direto às opiniões bem como às crenças, valores e significados que as entrevistados atribuem a si e aos outros (FRASER; GONDIM, 2004).

Elas foram realizadas em maio de 2011, na instituição de ensino que acolheu os intercambistas. Foram conduzidas individualmente e tiveram duração aproximada de uma hora, cada. Frente à visível disponibilidade dos entrevistados, as questões foram exaustivamente aprofundadas. Envolveu cinco estudantes estrangeiros que participavam de um programa de intercâmbio acadêmico de média duração (seis meses) em uma instituição de ensino superior localizada na cidade de São Paulo. Os entrevistados eram provenientes de países com forte tradição em mobilidade ativa e passivai: Alemanha, Áustria, Chile, França, e Holanda. No período em que as entrevistas foram realizadas eles se encontravam há mais de três meses no Brasil e na instituição educacional brasileira - consequentemente, já se encontravam relativamente ambientados.

O total de estudantes entrevistados formava a população de intercambistas, na instituição, naquele semestre. Destaca-se que o número que entrevistados não foi o critério determinante nesse processo, mas a possibilidade de descobrir e compreender os diferentes aspectos presentes no contexto da mobilidade acadêmica (FRASER; GONDIM, 2004). Desta forma, não houve seleção e sim contato presencial com todos eles.

As dezessete questões que deram forma ao roteiro objetivaram dispor de materiais que permitissem a elaboração do perfil dos intercambistas, a compreensão dos aspectos relacionados à imagem do país, para os estudantes, que determinaram a escolha pelo Brasil, além da identificação de uma potencial intenção em retornar ao País quando concluído o intercâmbio. $\mathrm{O}$ referencial teórico advém de autores que vem se destacando na investigação da internacionalização da educação superior e daqueles que se dedicam ao estudo da marca país, imagem do destino e comportamento do consumidor. Os dados estatísticos derivam de documentos como o Education at a glance 2011, OECD Indicators e Recueil des donneés mondiales sur l'éducation 2010, UNESCO.. O corpus da pesquisa é formado com base nas entrevistas dos estudantes estrangeiros. A partir das leituras dos textos acadêmicos e das próprias entrevistas, foi possível realizar a interpretação do discurso dos estudantes utilizando como referência as diferentes categorias de motivação em relação ao processo de decisão do programa de mobilidade internacional, assim como o sistema interativo dos componentes da imagem de destino, no caso do país escolhido para o programa. 


\title{
3 REFERENCIAL TEÓRICO
}

\subsection{TRANSPONDO FRONTEIRAS: MOBILIDADE ACADÊMICA INTERNACIONAL}

As Instituições de Ensino Superior, entidades complexas por natureza, vivem sob constantes desafios. No contexto de um mundo onde a velocidade da informação, a mobilidade do capital, mercadorias e de pessoas, as IES tentam acompanhar com a mesma agilidade as transformações de um mundo globalizado. Sobre essa questão, Ianni explica que:

\begin{abstract}
A noções do espaço e tempo, fundamentais para todas as ciências sociais, estão sendo revolucionadas pelos desenvolvimentos científicos e tecnológicos incorporados e dinamizados pelos movimentos da sociedade global. [...] As redes de articulações e as alianças estratégicas de empresas, corporações, conglomerados, fundações, centros e institutos de pesquisas, universidades, igrejas, partidos, sindicatos, governos, meios de comunicação impressa e eletrônica, tudo isso constitui e desenvolve tecidos que agilizam relações, processos e estruturas, espaços e tempos , geografias e histórias. (IANNI, 2002, p.249)
\end{abstract}

Dessa maneira, as alterações alcançam distintas dimensões da sociedade contemporânea, dissolvendo barreiras de ordem técnica, política ou legal, entre as nações (CASTRO, 2011). Ainda que as universidades da Europa medieval, desde a sua origem, serem instituições interterritoriais, quando atraiam estudantes e professores de distintas regiões, foi também no pós-guerra que a internacionalização do ensino superior se intensificou (GARCÍA-GUADILLA, 2005). Não seria exagero afirmar que a globalização na qual se vive contemporaneamente teve a sua base constituída no final da Segunda Guerra Mundial. Isso pode ser observado pelo aumento da mobilidade de estudantes, professores, programas e fornecedores, fomentado por um mundo cada vez mais integrado no plano econômico (ALTBACH; KNIGHT, 2006).

O reflexo dessa conjuntura no âmbito da educação superior apresenta-se na forma de uma inversão na lógica do serviço educativo que em uma perspectiva comercial passou a ser orientado pela demanda social e do mercado. O resultado dessas mudanças externa-se na preocupação das IES em privilegiar os interesses comerciais e estratégicos (KRAWCZYK, 2008). Nesse sentido, tentam equilibrar o cumprimento de sua missão, de gerar conhecimento, com a necessidade de sobreviver, no sentido de continuar a oferecer seus serviços educacionais. Stromquist ilustra esse cenário afirmando que:

There is consensus that higher education is undergoing substantial change in the face of globalization, which brings a greater emphasis on market forces to the process of educational decision-making. However, universities experience pressures in different ways, depending on whether they are private or public institutions. Among 
the public universities, there are significant trends toward decentralization, mergers, privatization, and accountability. Among private institutions, there are considerable pressures to position themselves as the universities of choice for students and to be highly competitive in the procurement of research funds, both of which generate complex dynamics in their functioning. Since private institutions are more dependent on external support than public institutions, they are forced to monitor current trends in the economic environment and look for new opportunities; hence, private universities by the nature of their organization are likely to be more sensitive to globalization forces (STROMQUIST, 2007, p.83).

O motivo principal para todos os projetos de internacionalização nas IES com fins lucrativos e também para algumas universidades tradicionais, sem fins lucrativos, mas com limitações financeiras, parece ser a obtenção de lucros por meios da comercialização se seus serviços. Muitos países, prospectam estudantes internacionais com essa intenção, cobrando taxas elevadas (ALTBACH; KNIGHT, 2006).

Seguindo pela lógica mercadológica, muitas instituições de ensino superior veem na internacionalização um meio de manter-se financeiramente, uma vez que investem na captação estudantes estrangeiros dispostos a pagar pela anuidades impostas, pela oportunidade de viver uma experiência acadêmica fora de seu país origem e de alguma forma amadurecer como pessoa e diferenciar seu currículo. Um exemplo dessa prática é o sistema de educação superior australiano. Conforme os dados do Education at a Glance, (OECD 2011), em 2009 o país a recebeu 257.637 estudantes estrangeiros. O que corresponde a 7\% do market share da educação internacional (OCDE, 2011). No entanto, cabe ponderar que além de estabelecer políticas de atração de estudantes, o lugar em questão possui aspectos externos que influem na atratividade da educação superior australiana, ou seja, a imagem positiva que o país esboça entre os jovens e suas famílias. Essa representação encontra-se associada à cordialidade dos australianos, à diversidade cultural do país, qualidade de vida associada à, segurança pública, à biodiversidade e os fatores climáticos, às atratividades de lazer etc. (LIMA; CONTEL, 2011).

Atuando na perspectiva de uma internacionalização ativa, a Austrália acolhe mais estudantes internacionais do que envia, ao contrário do Brasil. No entanto, embora o processo de internacionalização do ensino superior no Brasil transcorra lentamente, o fato é que esse parece um caminho perseguido pelas instituições mais reputadas, sejam elas públicas ou particulares. Isso é particularmente observado no ambiente marcado pelos programas de pósgraduação em que a formação de redes de pesquisa é induzida pelos critérios de avaliação adotados pela CAPES. Visto por esse prisma, talvez fosse factível fortalecer o sistema de educação para que ele tenha chance de seguir por uma trilha onde possa se integrar com 
outras esferas de ordem política, social e talvez, turística. Historicamente o país tem formulado políticas e implementado ações que promovem o envio de estudantes, professores e pesquisadores para os países com tradição acadêmica. No entanto, os esforços para atrair acadêmicos internacionais tem sido tímidos. Curiosamente, o Brasil pode ser muito atrativo para jovens universitários uma vez que reúne um grupo de universidades com destaque nos rankings mundiais e regionais, tem uma economia em crescimento, é um país multicultural acolhedor, com admirável biodiversidade.

A consulta a textos cujo conteúdo trata das motivações que justificam o crescimento da mobilidade internacional de estudantes, associada a resultados de levantamentos realizados tanto no Brasil quanto no exterior, convergem em alguns aspectos. Apesar da multiplicidade dos aspectos catalogados, é possível distribuí-los em quatro categorias: sociocultural, acadêmica, econômica e político-administrativa (LIMA; CONTEL, 2011). Mas a questão é escorregadia porque mesmo quando os jovens associam o interesse pelos programas de intercâmbio internacional ao aprendizado de uma língua estrangeira, por exemplo, essa aquisição não tem o mesmo significado para todos: enquanto para alguns ela é associada à elevação da empregabilidade ou à ampliação de chances de uma carreira internacional; para outros ela facilitará o contato com outra cultura, alguma integração intercultural, e experiências pessoais intensas. No contexto descrito, certamente há pouco em comum entre o que a literatura nomeia de peregrinação acadêmica (RIDDER-SYMOENS, 1996) e mobilidade acadêmica (SCOCUGLIA, 2008). Mesmo as manifestações nomeadas de mobilidade acadêmica variam de país para país em razão dos interesses implicados, seja dos estudantes e respectivas famílias, das instituições de educação superior e do Governo federal.

Com a preocupação de entender as escolhas dos estudantes internacionais que escolhem instituições de educação superior localizadas no Brasil para realizar uma experiência de mobilidade acadêmica, esta investigação privilegiou o contato com estudantes internacionais em séjour de estudo no Brasil. Levando em conta os limitados esforços institucionais ou de políticas nacionais para atrair estudantes internacionais, a investigação buscou compreender quais seriam possíveis questões que motivariam a escolha pelo país, que não está entre o grupo de países que mais recebe estudantes estrangeiros, ou não é um país que oferece cursos em inglês, língua estrangeira mais buscada pelos estudantes, principalmente aqueles de países semi-periféricos. As relações com o Brasil estariam 
relacionadas, portanto, a aspectos pessoais dos estudantes, ou a fatores relacionados à imagem do país, como possíveis elementos determinantes na decisão do país de destino.

\title{
3.2 A IMAGEM REFLETIDA: IMAGEM DE DESTINO NO PROCESSO DE DECISÃO PARA A MOBILIDADE
}

$\mathrm{Na}$ busca por estudos que orientem para um caminho que conduza para compreensão acerca da imagem do destino, perspectiva mais adequada à proposta de investigação no âmbito deste texto, percebe-se a complexidade que envolve o tema. $\mathrm{O}$ conteúdo do artigo de Tasci et al (2007) amplia a revisão da literatura realizada por Echtner e Ritchie (1991), e aprofunda em um artigo seminal as limitações e distorções que permeiam a discussão do tema.

Embora o objetivo deste artigo não seja discutir conceitualmente a imagem de destino, tampouco ampliar a revisão da literatura realizada pelos autores citados, é factível que se resgate a definição de imagem do destino e que se proceda com algumas considerações no objetivo de aproximá-lo ao tema aqui tratado. A partir de uma base conceitual, Echtner e Ritchie (1991) formularam o conceito de imagem de destino nos seguintes termos,

\begin{abstract}
not only the perceptions of individual destination attributes but also the holistic impression made by the destination. Destination image consists of functional characteristics, concerning the more tangible aspects of the destination, and psychological characteristics, concerning the more intangible aspects. Furthermore, destination images can be arranged on a continuum ranging from traits which can be commonly used to compare all destinations to those which are unique to very few destinations (ECHTNER;RITCHIE, 1991 p. 8)
\end{abstract}

Essa definição reflete o esforço de diversos estudiosos sobre esse tema. O desafio de formular um conceito capaz de expressar com precisão o que é imagem de destino se desdobra em outras questões no que concerne à operacionalização do conceito (MOSSBERG; KLEPPE, 2005). A imagem de destino possui a perspectiva da representação de diversos valores e características do país, visíveis e percebidas em diferentes contextos, por diferentes meios e mediações.

A década de 1990 foi especialmente fértil em número de estudos sobre imagem de destino. Esse aspecto, no contexto de mercados que trabalham as potencialidades turísticas, pode ser determinante no que concerne a alterar o comportamento do consumidor. Talvez, isso explique o interesse de pesquisadores oriundos de diversas áreas do conhecimento. No entanto, a diversidade de estudos não consolidou o constructo imagem de destino. $\mathrm{O}$ uso de diversas e novas terminologias não contribuiu no sentido de fortalecer o corpo da literatura, 
pois se o conceito variava de autor para autor, os procedimentos metodológicos utilizados na coleta de dados empíricos, não seguiam por caminhos diferentes. Logo, os resultados poderiam incidir em vieses que levassem a interpretações equivocadas (TASCI et al ,2007).

$\mathrm{Na}$ intenção de contribuir para o desenvolvimento de um modelo que sintetizasse os componentes presentes na imagem de destino e dessa forma, proporcionasse a realização estudos de maneira integrada, Tasci et al (2007) propuseram que a imagem de destino seja apreendida como um sistema interativo entre pensamento, opiniões, sentimentos, visualizações e intenções em direção ao destino. Para eles é impossível investigar esses elementos isoladamente. Orientados por essa premissa, os autores ilustram suas ideias em um sistema interativo de componentes da imagem, conforme a figura 1. Nessa perspectiva, o principal componente desse sistema é o conhecimento sobre os atributos comum e único do destino. Os sentimentos em relação aos atributos conhecidos compõem a imagem de forma holística.A interação entre esses componentes se dá de forma em que um afeta o outro e conseqüentemente impacta na decisão (TASCI et al, 2007).

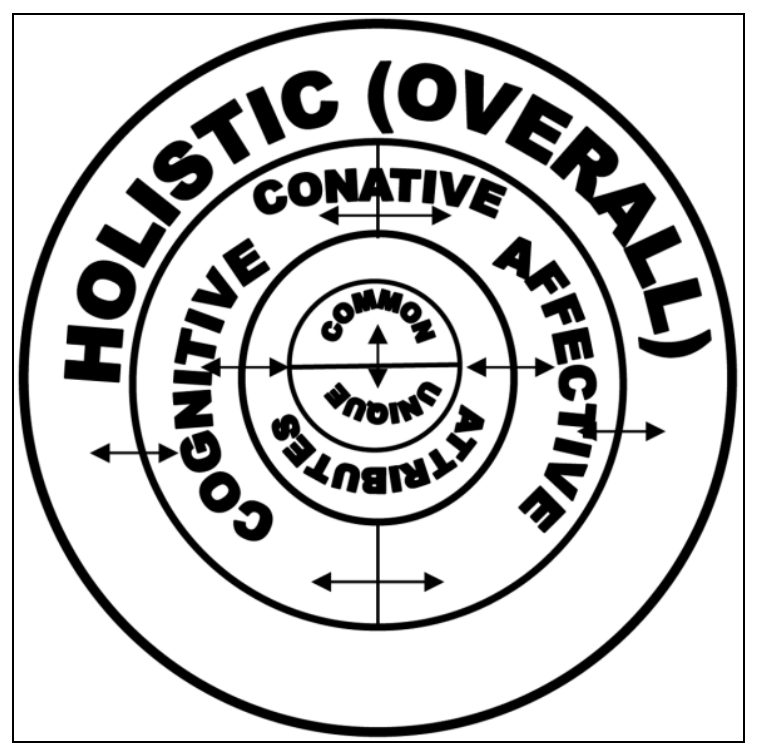

Figura 1 Sistema Interativo de Componentes da Imagem Fonte: Tasci at al (2007, p. 200)

Ainda que sob uma breve explanação, é possível dimensionar a extensão do tema e a riqueza de um campo carente de estudos dotados do rigor científico. Ao se pensar no âmbito de Brasil, as investigações sobre a imagem do país como destino são raras. O que existem são pesquisas realizadas com financiamento privado para benefício de quem as financia. Os governos realizam apenas alguns estudos estatísticos, o que proporciona o registro 
quantitativo descritivo, tão somente. Além disso, os estudos apresentam limitação no que diz respeito à confiabilidade (PEREZ-NEBRA; TORRES, 2010).

Contudo, se a imagem é relevante na escolha do destino na perspectiva do turismo, torna-se oportuno questionar em que medida a imagem de destino pode influenciar na decisão de estudantes internacionais em mobilidade acadêmica. Esse elemento, tão emblemático para o turismo (mercado e consumidor) seria igualmente considerado pelos estudantes estrangeiros?

O investimento em turismo pelas administrações de cada país representa o volume de recursos e esforços que são colocados na imagem de destino, fato que demonstrar que esses governos acreditam na promoção da imagem do país como ferramenta (MOSSBERG; KLEPPE, 2005). Esse esforço também reforça ou amplia as oportunidades de atração de estrangeiros para o país, relacionando fatores locais, no caso do Brasil, aspectos como riquezas naturais e festividades, como é possível analisar no material institucional do órgão responsável por turismo no país (www.braziltour.com).

Uma pesquisa desenvolvida de investigações sobre a imagem do Brasil com 140 estudantes australianos por Leal (2004) combinou recursos metodológicos qualitativos e quantitativos. Considerando os resultados da interpretação dos materiais obtidos com as questões abertas, a principal característica da imagem do Brasil foi a cultura. A análise dos dados quantitativos, por sua vez, sinalizou a existência de seis fatores, a saber: (1) reputação, atratividades e locais; (2) infraestrutura e facilidade; (3) ambiente natural, oportunidade de ganhar conhecimento e para aventura; (4) bons preços, entretenimento e festivais; (5) gastronomia, restaurantes e acomodação; (6) cidades desenvolvidas e atrativas (LEAL, 2004 apud PEREZ-NEBRA; TORRES, 2010).

Embora todo empenho canalizado para a compreensão do fenômeno seja válido, não há como assegurar que os fatores identificados (e referenciados no parágrafo anterior) estejam em consonância com os resultados alcançados por investigações realizadas com estudantes oriundos de outros países. Ou seja, as variáveis envolvidas na percepção da imagem de destino podem ser influenciadas por diversos fatores. Um deles são os meios de comunicação, uma vez que eles desempenham um papel particularmente importante na formação de tal percepção, essencialmente quando esta é negativa. Dessa maneira, as pessoas podem formar imagens de um país que não correspondam à realidade. Pois, freqüentemente, baseiam-se em informação desatualizada, realizando interpretações ao invés de deter-se aos 
fatos. O problema, nesse caso, é o compartilhamento dos estereótipos por muitos membros de uma mesma sociedade (GERTNER; KOTLER, 2002).

\section{ANÁLISE DOS DADOS}

\subsection{ASPECTOS PESSOAIS}

A partir da análise do material coletado por meio das entrevistas com os estudantes estrangeiros que escolheram o Brasil como país de destino para seu programa de mobilidade acadêmica internacional, é possível verificar diversos aspectos que os motivaram a decidir pelo país. Dentre esses aspectos, inicialmente são avaliadas as questões pessoais, que em diferentes casos, entre os estudantes, é o fator inicial que cria o interesse e a curiosidade pelo país. Amigos e conhecidos brasileiros, que falam do país e que representam também seus fatores culturais mostram a nesses estudantes estrangeiros a possibilidade do Brasil como país destino, principalmente pelos fatores pessoais e relacionais.

Os estrangeiros se interessam pelas características culturais do Brasil, como a amizade e as festividades, além de pensar no país como um local de clima agradável, onde há possibilidades distintas de diversão.

A identificação de laços pessoais para o processo de decisão do país de destino ocorre em diferentes níveis e aspectos da vida dos estudantes. No caso do estudante a seguir, os fatores relacionais e familiares foram relevantes para a escolha do Brasil:

Conheci minha namorada, uma brasileira, num jogo de futebol. Ela estava
passeando, de férias. Começamos a namorar, faz quatro anos que estamos juntos. Na
época ela já estudava nessa instituição onde estou aqui no Brasil (...) Eu queria vir
para o Brasil para ficar com a minha namorada e também por que eu queria ver meu
pai.

Há também aspectos relacionais e de relação com a possibilidade de entretenimento e mesmo de autonomia, quando se fala no Brasil como um local de festas e de clima agradável. Além disso, o estudante também menciona a distância como um fator que cria interesse, tanto pelos aspectos divergentes de sua cultura, quanto pela possibilidade de vivenciar a experiência da mobilidade dentro de um contexto distinto, sem a proximidade dos pais: "No Brasil faz calor, é parte do BRIC, tem Carnaval, sol e é longe".

Apesar do Brasil não figurar dentre os países de maior recepção de estudantes em mobilidade acadêmica internacional, a rede de conexões sociais e pessoais pode ser um dos fatores que cria interesse pelo país. Enfatizando os aspectos pessoais, os fatores culturais 
brasileiros, que valorizam as relações e a diversão, também são aspectos que motivam os estrangeiros a conhecer o país e a decidir por um séjour de longa duração.

\subsection{ASPECTOS ACADÊMICOS}

A partir da rede de conhecimento dos estudantes estrangeiros, também criou-se interesse pelos aspectos acadêmicos, além dos pessoais. Amigos e conhecidos brasileiros, que estudam na instituição escolhida para o programa de mobilidade, são destacados como influenciadores nessa decisão, pela reputação que criam em relação a essa instituição. Também existem fatores acadêmicos que são considerados pelos estudantes ao escolher a instituição como destino de mobilidade, que são os convênios existentes com a sua instituição de origem, e a especialidade na área de estudo de interesse.

Revelando que a imagem da instituição e a motivação para se investir em determinado período de estudo nesse local é resultado das indicações dos estudantes brasileiros que já foram ou ainda são parte de seu corpo discente, é possível verificar como os fatores relacionais ainda são relevantes para a escolha do Brasil como país de destino, assim como da instituição específica:

Os brasileiros que eu conheci, sempre diziam que essa instituição é uma ótima escola. Bom, e minha namorada estuda aqui e me disse que a faculdade é muito boa. Eu tenho uma amiga que mora em Porto Alegre e estuda nessa instituição, no Sul. Ela sempre me falou muito bem da faculdade.

A aluna daqui que eu conheci na minha faculdade, me falou muito bem da instituição.

Estive no Brasil, no Rio de Janeiro, em férias, e meus amigos me indicaram a fazer um curso nessa instituição.

O desenvolvimento de parcerias e convênios com instituições estrangeiras também é um caminho para a recepção de estudantes estrangeiros em mobilidade. A instituição objeto desse estudo possui atualmente convênios com universidades na América do Sul, na Europa, na América do Norte e na Ásia. O investimento institucional na internacionalização, tanto para o envio de seus estudantes, quanto para a recepção de estudantes de outros países é também um dos aspectos que refletem sobre a imagem da instituição de ensino, tanto para seu corpo discente, quanto para estudantes estrangeiros. O convênio pode facilitar a decisão do estudante que decide participar de um programa de mobilidade, pela aproximação e pelo conhecimento existentes, principalmente em relação a aspectos burocráticos ou financeiros relacionados ao programa. A escolha da instituição pode ocorrer também por sua área de especialidade, sendo esse fator um dos aspectos acadêmicos para a decisão sobre o programa 
de mobilidade, dependendo da necessidade da formação superior do estudante, ou de seus interesses específicos. No caso da instituição objeto do estudo, uma das áreas de maior ênfase em seus cursos é a mercadologia, fator que a diferenciou no momento de escolha dos estudantes estrangeiros:

\begin{abstract}
A universidade onde eu estudo tem acordos com outras faculdades, mas eu escolhi essa instituição porque ela é uma referência em marketing.

Eu queria uma escola especializada em marketing propaganda e ouvi que essa instituição é muito boa nesta área.
\end{abstract}

Há diversas instituições de ensino superior que buscam no seu processo de internacionalização um padrão mundial, e se empenham tanto em enviar seus estudantes para outros países, quanto em atrair estudantes solvíveis. Tal trilha das universidades padrão mundial (Charle et al., 2004) é enaltecida com a proliferação dos rankings mundiais. No caso da instituição escolhida, apesar dela não figurar em nenhum desses rankings, como uma instituição de destaque internacional, a rede pessoal e social de seus estudantes foi um dos fatores de valorização de sua reputação. Além disso, seus esforços no desenvolvimento de convênios internacionais, além de sua especialização em áreas específicas de conhecimento também motivaram estudantes para escolhê-la como instituição de destino.

\title{
4.3 IMAGEM DE DESTINO
}

No grupo de estudantes investigados no âmbito desse artigo, é possível identificar em seus discursos, os elementos presentes no sistema interativo de componentes da imagem, conforme apresentado anteriormente e ilustrado na fig.1. Nessa perspectiva, observa-se que o componente holístico está presente nas narrativas dos estudantes, quando questionados sobre a imagem faziam do Brasil. É possível ainda identificar a presença dos demais componentes do sistema quando o estudante revela que: "Me interessa ( $\mathrm{sic}$ ) saber como funciona o sistema financeiro do Brasil. O sonho do mundo está aqui. É aqui que as coisas acontecem”.

Talvez, no momento em que o estudante formou essa imagem sobre o Brasil, o país era mesmo um lugar único na perspectiva relatada. Nota-se nessa mensagem, a presença do elemento conativo, ou seja, a intenção de vir para o Brasil a partir do conhecimento desses atributos.

"No Brasil faz calor, é parte do BRIC, tem Carnaval, sol e é longe”. Nessa afirmativa, o estudante revela o que para ele pode representar um laço afetivo. 
“O Brasil é um país emergente com uma situação econômica muito boa. É diferente dos que já conheci”. O componente presente nessa explanação parece estar relacionado a um atributo incomum. Para esse jovem, ter a oportunidade de conhecer um país em uma situação econômica boa, pode ser um atributo único.

“Antes de conhecer o Brasil eu achava que aqui era uma imensa floresta". No âmbito dessa explicação, observa-se o componente cognitivo. Isso foi depreendido por esse estudante e talvez esse pensamento seja compartilhado por muitas pessoas. Quanto às questões sobre as percepções sobre o Brasil, a intenção de retornar ao País são reveladoras de uma imagem predominantemente positiva:

\footnotetext{
(...) o mais incrível aqui são as pessoas. O povo é muito amigável. Eu notei que aqui as pessoas fazem parte de vários grupos. O grupo dos amigos, da família, da escola, do trabalho e elas fazem questão de manter um bom relacionamento com todos esses grupos. (...) eu gosto muito da comida brasileira, principalmente das frutas. Eu pretendo voltar ao Brasil, talvez até para morar, futuramente.

O povo brasileiro está sempre feliz. É muito otimista. Mesmo que esteja em uma situação difícil sempre fala que vai dar tudo certo. Eu estou amando esse período no Brasil e quando eu puder, vou voltar.

Vou voltar para o Brasil com certeza, por que o Brasil é um país ótimo e tem oportunidades interessantes. Dá para fazer dinheiro em são Paulo. A imagem do Brasil era das praias do RJ, água de coco, caipirinha... Agora vejo uma cidade cara, com pessoas que trabalham muito. Eu acho que no Brasil as pessoas trabalham muito, mas aproveitam a família, os amigos.

O Brasil é um lugar muito interessante onde as pessoas são muito amigáveis. Um dia virei morar aqui.

Honestamente, não pretendo voltar ao Brasil. Na Europa, todos são muito independentes. Aqui, tudo é feito em grupo e eu prefiro fazer as coisas sozinha. (...) outra coisa é que no Brasil as pessoas simplesmente dizem coisas que não pretendem cumprir e isso é muito difícil pra mim.
}

A interpretação do discurso desses estudantes no que diz respeito à percepção sobre o Brasil, passa necessariamente pelo aspecto cultural onde a principal referência são as pessoas. Embora estejam presentes também os aspectos relacionados a elementos típicos do país praias do Rio de Janeiro, a água de coco, e a caipirinha, por exemplo - o foco principal está nos brasileiros, tanto ao ressaltar os aspectos positivos quanto o aspecto negativo.

Traços da cultura brasileira como o relacionamento pessoal e a flexibilidade, distinguem os brasileiros. Sobre o relacionamento pessoal, esse traço, fundamental dos brasileiros, é reconhecido por estrangeiros que visitam o Brasil. Eles identificam os brasileiros como um povo amigável, hospitaleiro e inclusivo, tanto nas relações pessoais quanto nas profissionais. No que tange à flexibilidade, essa característica é expressa no chamado “jeitinho brasileiro". Ou seja, é uma espécie de caminho do meio entre o que é e o que não é permitido. Esse jeitinho, traduzido pela informalidade associada à espontaneidade pode ser 
expresso por meio da comunicação, linguagem, forma de vestir, uso de tempo, etc. Sobre essa característica, ao mesmo tempo que pode representar um aspecto negativo, pode também revelar a capacidade de adaptação dos brasileiros, acentuadas pelas diversas mudanças de governos e na economia (TANURE; DUARTE, 2005).

Curiosamente, esse aspecto não parece muito evidenciado na promoção do Brasil. Prova disso é que não foi referenciado pelos estudantes quando o tópico tratava da imagem. Gertner (2004) resgata, em uma perspectiva crítica, questões relativas à imagem do país. Segundo o autor, o Brasil está associado a atributos de imagem positivos ou neutros. Esses podem ser praia, carnaval, belezas naturais, futebol e música, ou a personalidades públicas como Pelé, Ronaldo, Zico e Gisele Bündchen (GERTNER, 2004). Nota-se que no que concerne a pessoas, são ícones brasileiros e não necessariamente retratam a essência dos brasileiros. Há também, outros atributos associados ao país, porém, são negativos, tais como crime, violência, degradação ambiental, fome e miséria (GERTNER, 2004) desconsiderados pelos entrevistados.

Questões como as resgatadas acima, revelam a complexidade do tema imagem do destino e a importância de considerar esse aspecto no planejamento para a atração de estudantes ao Brasil.

\section{CONSIDERAÇÕES FINAIS}

Os fatores que motivam estudantes estrangeiros a escolher o Brasil como destino de seu processo de mobilidade espontânea internacional para um séjour de estudo revelam tanto questões pessoais e acadêmicas como relações importantes na escolha, assim como a imagem do país como um diferencial entre outras opções de destino.

A escolha do Brasil ocorre, apesar da desigualdade da força simbólica existente entre as nações uma vez que todos estão situados no hemisfério norte; tem economias fortes e estão entre os países centrais; tem sistemas educacionais que ultrapassaram o nível da massificação e precisam conquistar novos mercados para justificar os históricos investimentos públicos e privados recebidos; tem instituições de educação bem classificadas nos rankings mundiais; governos que institucionalizaram agressiva política de atração de estudantes internacionais; acumulam reconhecida experiência na recepção de estudantes internacionais e por isso mesmo os campi universitários reúnem estudantes de todos os continentes; os países tem o inglês como língua oficial e as universidades oferecem cursos de e em inglês (LIMA, CONTEL, 
2011). Os estudantes que optam por um programa de mobilidade acadêmica no Brasil não avaliam, dessa forma, os mesmos aspectos que a maioria dos estudantes em processo de mobilidade pelo mundo.

O estudo sobre imagem de destino parece estar em consonância com o estudo sobre a mobilidade acadêmica, no que concerne a necessidade do estabelecimento de um constructo robusto. As limitações teóricas e metodológicas que circundam essas investigações proporcionam um campo fértil para a proliferação de estudos. No entanto, ambos são carentes de um corpo consistente, tanto na literatura, por que apropriados por diversas áreas de conhecimento, que utilizam as mais variadas terminologias, quanto metodológico, por que respaldado em sua maioria por quantificações descritivas. Sob esse aspecto Tasci et al, 2007, recomendam o uso combinado de métodos quantitativos e qualitativos nas investigações sobre a imagem do destino.

Os desafios em compreender tanto a mobilidade acadêmica quanto a imagem do país de destino, passam também pela reflexão sobre o quanto cada um desses temas pode ser relevante para o outro ou mesmo influenciado. Visto por esse ângulo, se o estudo dos componentes presentes na imagem do destino não podem ser investigados isoladamente, talvez o estudo a respeito da internacionalização do ensino superior na perspectiva do acolhimento dos estudantes, também não possa se dissociado da imagem de destino. Como observado no discurso dos estudantes que compuseram essa investigação, não é possível identificar um padrão nas motivações para a escolha do Brasil como destino para um período de estudos. $\mathrm{O}$ que reflete a necessidade de ampliar a pesquisa tanto em termos quantitativos quanto aprofundar qualitativamente, visando compreender os elementos adjacentes à escolha dos estudantes.

\section{REFERÊNCIAS}

ALTBACH, P. G.; KNIGHT, J.: The Internationalization of Higher Education: Motivations and Realitie. The NEA 2006 Almanac of Higher Education, 2006.

CASTRO, A. M. D. A. Da ótica da solidariedade à lógica do mercado: as estratégias de internacionalização do ensino superior. Disponível em http://www.anpae.org.br/simposio2011/cdrom2011/PDFs/trabalhosCompletos/comunicacoes Relatos/0016.pdf - acessado em novembro de 2011

CHARLE, Cristophe et al. "Ensino superior: o momento crítico" In: Educação \& Sociedade, Campinas, v.25, n.88, Especial, out. 2004, p.961-975, 2004. 
COWEN, M.F.: Latin American Universities, Academic Freedom and Autonomy: a long term myth? Comparative Education. Vol 38, no 4, p. 471-484, 2002

ECHTNER, C. M.; RITCHIE, J. R. B. The meaning and measurement of destination image. The Journal of Tourism Studies, 2(2), 2-12, 1991.

FRASER, M.T.D.; GONDIM, S.M.G. Da fala do outro ao texto negociado: discussões sobre entrevista na pesquisa qualitativa, In: Paidéia, v.14, n.28, 2004, p.139-152.

GARCÍA-GUADILLA, C. Complejidades de la globalización e internacionalización de la educación superior interrogantes para América Latina. Cuadernos del Cendes, vol. 22, n. 58, jan.abr. 2005. p.1-22.

GODOI, C. K.; MATTOS, P. L.C.L. de. Entrevista qualitativa: instrumento de pesquisa e evento dialógico In: GODOI, C.K. et al. Pesquisa qualitativa em estudos organizacionais paradigmas, estratégias e métodos. São Paulo: Saraiva, 2006 - p.301-323.

IANNI, O. Teorias da globalização. 10ª ed. Rio de Janeiro: Civilização Brasileira, 2002.

KOTLER, P.; GERTNER, D. Country as a brand, product, and beyond: A place marketing and brand management perspective. Journal of Brand Management, v.9, n.4/5, p. 249-261, 2002.

KRAWCZYK, N.R. As Políticas de Internacionalização das Universidades no Brasil: o caso da regionalização no Mercosul. Políticas Educativas, v. 1, p. 32-47, 2008.

LEAL, S. A imagem de destinações turísticas: um estudo de caso do Brasil na percepção de alunos baseados na Austrália. Retur, 2(2), 1-8, 2004.

LIMA, M. C.; CONTEL, F. B. Internacionalização do ensino superior: Nações ativas, nações passivas e a geopolítica do conhecimento. São Paulo: Alameda, 2011.

MOSSBERG, L.; KLEPPE, I. A. Country and Destination Image - Different or Similar Image Concepts? The Service Industries Journal, v.25, n.4, p.493-503, 2005.

OCDE. Education at a glance 2010: OECD Indicators. Paris: OECD, 2010.

PÉREZ-NEBRA, A. R.; TORRES, C.V. Medindo a Imagem do Destino Turístico: uma Pesquisa Baseada na Teoria de Resposta ao Item. $R A C$, Curitiba, v. 14, n. 1, art. 5, pp. 80-99, Jan./Fev. 2010

SCHWARTZMAN, S. A universidade primeira do Brasil: entre intelligentsia, padrão internacional e inclusão social. Estud. av. [online]. vol.20, n.56, 2006, pp. 161-189.

SILVA, C. C. dos S.; LIMA, M. C. A influência da network sobre a decisão de investimento em programas de mobilidade acadêmica In: XI Colóquio Internacional sobre Gestão Universitária na América do Sul e II Congresso Internacional IGLU, 7, 8 e 9 de dezembro 2011, Florianópolis, Anais... Florianópolis, 2011. 
STROMQUIST, N.P. Internationalization as a response to globalization: Radical shifts in university environments. Higher Education, 53 (1), 2007, p.81-105.

TANURE, B.; DUARTE, R. G. Leveraging competitiveness upon national cultural traits: the management of people in Brazilian companies. International journal of human resource management, v. 16, n. 12, p. 38-54, 2005.

TASCI, A. D. A.; GARTNER, W. C.; CAVUSGIL, S. T. Conceptualization and Operationalization of Destination Image. Journal of Hospitality \& Tourism Research. V. 31, p. 194, 2007.

WIT, H. de: Internationalisation of Higher Education in Europe and its assessment, trends and issues - December, 2010 - disponível em:

http://www.nvao.net/page/downloads/Internationalisation of Higher Education in Europe DEF december 2010.pdf - acessado em novembro de 2011

\footnotetext{
${ }^{\mathrm{i}} \mathrm{O}$ conceito de internacionalização ativa e passiva foi desenvolvido por Lima e Maranhão em artigo intitulado de O Sistema de Educação Superior Mundial: entre a internacionalização ativa e passiva, publicado na revista Avaliação: Revista da Avaliação da Educação Superior na edição de novembro de 2009.
} 